Session 2320

\title{
Web-based Distance Learning Environment Using a Database to Teach Educators about Electronic Media
}

\author{
Rujin Cheng, Tze-Leong Yew, Kurt Gramoll \\ Aerospace and Mechanical Engineering \\ University of Oklahoma
}

\begin{abstract}
Education continues to change with the availability of new teaching techniques and emerging technology. Over the past few years, the Internet has become an increasingly popular medium for distance learning. This paper describes the distance learning initiative at the University of Oklahoma to help teach and train educators about electronic media. In particular, demonstrated use of an integrated database on a web server presents new opportunities to learn and research teaching methods in an asynchronous perspective. The database allows the development of a large scale-learning environment that can facilitate user tracking, community collaboration, and assessment. In particular, the system coordinates the learning activities of each user to help assist them in understanding ten different media types. The learning methods utilize case studies, tutorials, and concept pages which are independently monitored for user activities. The scope of this paper extends to the front-end and server-side development of the distance-learning site. The paper also examines the different development phases as well as the technologies and software tools used in the building of such a site.
\end{abstract}

\section{Introduction}

For many years, instructors from different levels of education have used various techniques to educate students from remote locations. With declining budgets for education, many are turning towards technology as a means to reduce time, cost and teaching resources needed to educate students. This has produced a rapid increase in the number of distance learning initiatives on both federal and state level education systems.

The increase in distance learning can be attributed to the growing popularity of the Internet. Deborah Coppula ${ }^{[1]}$ believes that the rapid growth of the Internet is an incentive to change the fundamentals in course design. This change should affect both the structure of the classroom and the educator.

This paper presents research in the development of an online distance-learning site using webbased databases, which was developed at the University of Oklahoma. This asynchronous 
learning environment was created to facilitate teaching educators how to use multimedia elements and multimedia development tools to create interactive content for use in their courses. The online environment is based, in part, on the successful multimedia course for engineering students that have been conducted at the University of Oklahoma for the last fours years ${ }^{[2]}$. It is expected that through the use of the Internet, the course content can be accessed by other instructors to learn how to develop and implement electronic media into their own courses.

The distance learning site named "Electronic Media Education for Teachers" or EMET, is made possible through a grant from the Hitachi Foundation. EMET is a three-year project that began in January 2000, and is a joint collaboration between the College of Engineering and the College of Education at the University of Oklahoma. Figure 1 shows a screenshot of EMET.

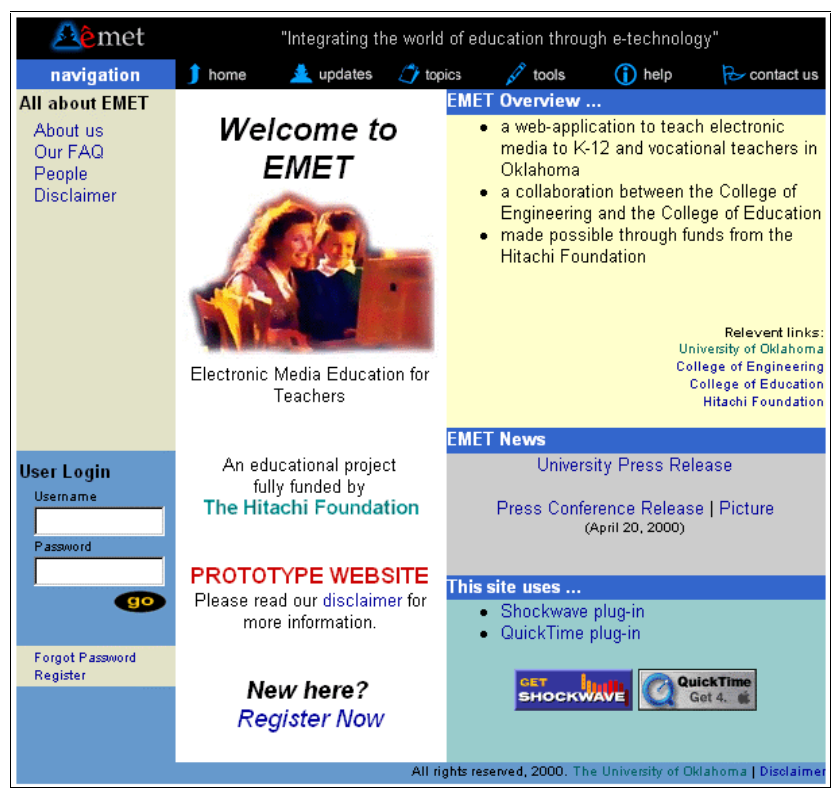

Fig. 1. EMET Distance Learning Site

In the development of EMET, current available Internet technologies were used. Among these technologies are the relational database management (RDBMS) and server-side scripting languages that were used to provide functionality to the front-end website from the back-end RDBMS system. Similar applications are used commonly in online electronic retailing and procurement to organize and track the presence of clients.

This paper presents a summarized methodology that was used to build the site. In particular, emphasis is given to the use of a database on the web server. The design and development of the back-end database system incorporates user tracking and logging of historical data for future analysis. The creation of educational content for EMET will also be covered, with emphasis on the development and integration of the simulation tutorials to the back-end database. In addition, this research demonstrates how hardware and server-based components and software can be utilized to develop and broadcast EMET to the world. 


\section{Topic areas of EMET}

The development of electronic media involves more than just one or two media types. Modern web sites and courseware need a large range of media, including both 2- and 3D animation, graphics, diagrams, text, simulations, video and sound to keep the interest of the student. To support this wide range of media, EMET website covers ten major multimedia development tools as described in Table 1. These particular media types and tools were chosen to insure that all major media types are covered using the most effective software tool available. All media types and tools are not tied to a particular discipline and thus teachers can use them to develop their own individual courses material regardless of content.

\begin{tabular}{|c|c|c|}
\hline Phase & Tools & Descriptions \\
\hline \multirow[t]{4}{*}{ Beginning } & $\begin{array}{l}\text { Dreamweaver } \\
\text { (HTML) }\end{array}$ & $\begin{array}{l}\text { - Advanced web page builder } \\
\text { - } \quad \text { Drag-and-drop type of interface } \\
\text { - WYSIWYG program }\end{array}$ \\
\hline & $\begin{array}{l}\text { Freehand } \\
\text { (drawing) }\end{array}$ & $\begin{array}{l}\text { - Illustration tool } \\
\text { - Objects are vector-based } \\
\text { - Files are small }\end{array}$ \\
\hline & $\begin{array}{l}\text { Photoshop } \\
\text { (photo editing) }\end{array}$ & $\begin{array}{l}\text { - Image editing and photo effects } \\
\text { - Graphics are pixel-based }\end{array}$ \\
\hline & $\begin{array}{l}\text { SoundForge } \\
\text { (sound editing) }\end{array}$ & $\begin{array}{l}\text { - Basic recording and editing } \\
\text { - Simple to use }\end{array}$ \\
\hline \multirow[t]{3}{*}{ Intermediate } & $\begin{array}{l}\text { Flash } \\
(2-D \text { animation })\end{array}$ & $\begin{array}{l}\text { - Vector-based animation program } \\
\text { - Supports sound and interactions }\end{array}$ \\
\hline & $\begin{array}{l}\text { Premiere } \\
\text { (video editing) }\end{array}$ & $\begin{array}{l}\text { - Industry standard for video editing } \\
\text { - Producing new videos from parts of others } \\
\text { - Special effects }\end{array}$ \\
\hline & $\begin{array}{l}\text { Excel } \\
\text { (data visualization) }\end{array}$ & $\begin{array}{l}\text { - Creates worksheets and charts that include } \\
\text { calculation features and formatting }\end{array}$ \\
\hline \multirow[t]{3}{*}{ Advanced } & $\begin{array}{l}\text { Director } \\
\text { (simulation) }\end{array}$ & $\begin{array}{l}\text { - Scripting capabilities for complex simulations } \\
\text { - Easy manipulation of graphics, sound, movies } \\
\text { - Interactivity }\end{array}$ \\
\hline & $\begin{array}{l}\text { Carrara } \\
\text { (3-D animation) }\end{array}$ & $\begin{array}{l}\text { - 3-D animation } \\
\text { - Both modeling and rendering }\end{array}$ \\
\hline & $\begin{array}{l}\text { JavaScript } \\
\text { (web scripting) }\end{array}$ & $\begin{array}{l}\text { - Basic interpreted programming language } \\
\text { embedded into HTML coding } \\
\text { - Dynamic web pages, interactivity } \\
\text { - OOP (Object-oriented Programming) }\end{array}$ \\
\hline
\end{tabular}

Table 1. Topics covered at the EMET Website 


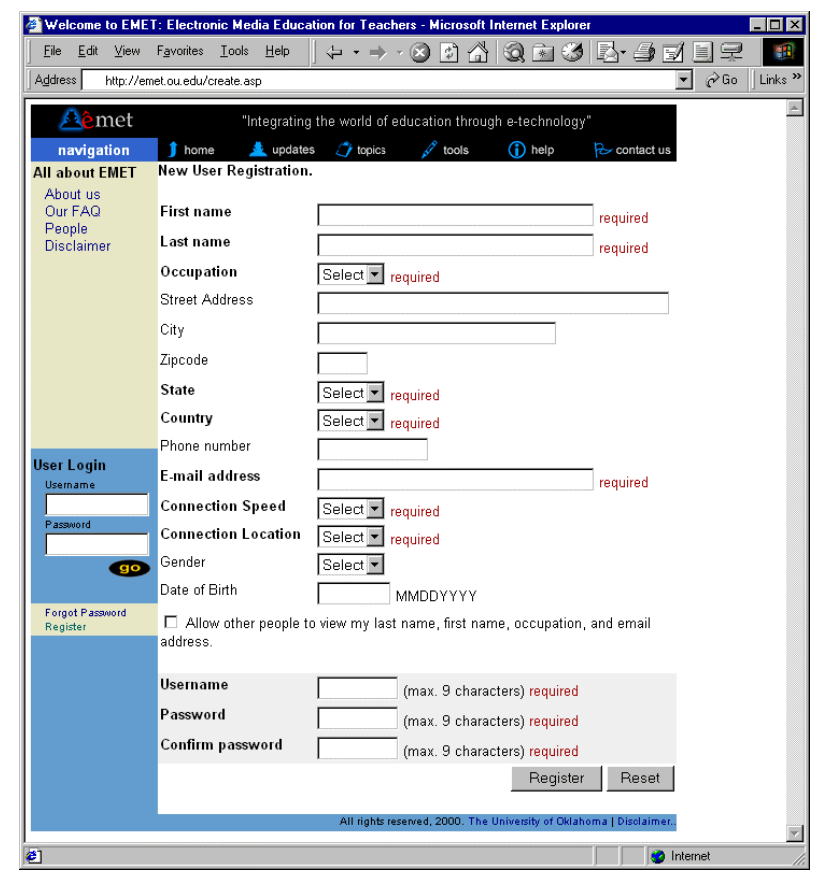

Fig. 2. New User Registration Page

\section{EMET Teaching Strategy}

EMET is built to show educators how to use and implement current information technology to assist in their teaching. It is not designed to be a classroom tool. It is more like a dictionary instead of a textbook. The editor of a dictionary will never gather his/her possible audience together to teach them the content of the dictionary page by page. Instead, he or she will just tell them that there is such a book. They can turn to it for help whenever they want to use some new, better words or sentences to make their speech or works more clearly and lively.

Similarly, the users of EMET are not asked to sit together and listen to lectures. There is no general schedule required for all users. Each specific user can have his/her own learning schedule. Furthermore, the users are not required to learn the offered topics step by step, from the beginning to the end. They can jump from one spot to another to get information they need. In a word, EMET is developed for asynchronous learning.

Through an investigative study into the various different types of learning methods early in the project, it was decided that there would be three distinctly different types of methods that will be employed on EMET. They are the concept pages, tutorial simulation and case studies. Each method differs in the degree of interactivity. However, it was important to keep the learning process flexible, effective, and responsive to the needs of the student and sensitive to time and location constraints ${ }^{[3]}$. This means a focus shift from teacher to learner. 
Effort is placed on separating the differing learning methods so that each method complements the other instead of replicating the same educational material. These different methods are shown with screen captures in Figs. 3, 4 and 5.

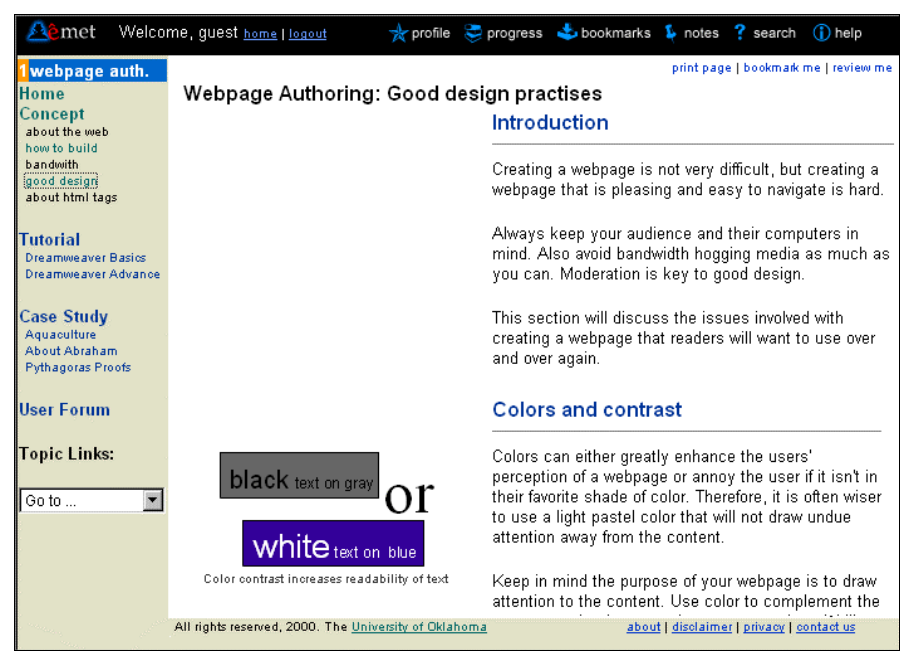

Fig. 3. Sample of a Concept Page

The concept pages describe a certain technology or multimedia element in greater detail through textual references. These pages give the user a general view, technical information, enlightening ideas and/or useful tips about a certain topic area. Sometimes it is not easy to deliver such conceptual knowledge to the user merely through simulations and case studies, thus the concept pages are used to supplement the interactivity of the tutorials and diversity of the case studies. The concept pages may moderately include multimedia elements, such as graphics, to provide a better description and demonstration of the topic in question.

The tutorial simulations on the other hand, offer a noticeable increase in interactivity as compared to the concept pages. The simulations were developed using Macromedia Shockwave technology, which will be discussed in greater detail in the next section. The purpose of the tutorials is to teach the user how to use a certain multimedia development tool such as Dreamweaver or Photoshop. The tutorials mimic the software interfaces so that the user can relate the tutorials to the real multimedia software. Each tutorial consists of several objectives; in each objective there are several goals that the users have to achieve, such as how to change the background color of a web page (Dreamweaver). Upon completion of the objective, a short quiz is administered to find out how well the user understands the objective.

The last learning method is the case study. Case studies were used because they offer a good opportunity to show real world application of the topic in question. They were developed to show how a combination of different media elements could be used to illustrate concepts and teaching methods. For example, in teaching the user how to create a web page it would be beneficial to show the user how web pages that have been created by their peers to present ideas on the Internet. 


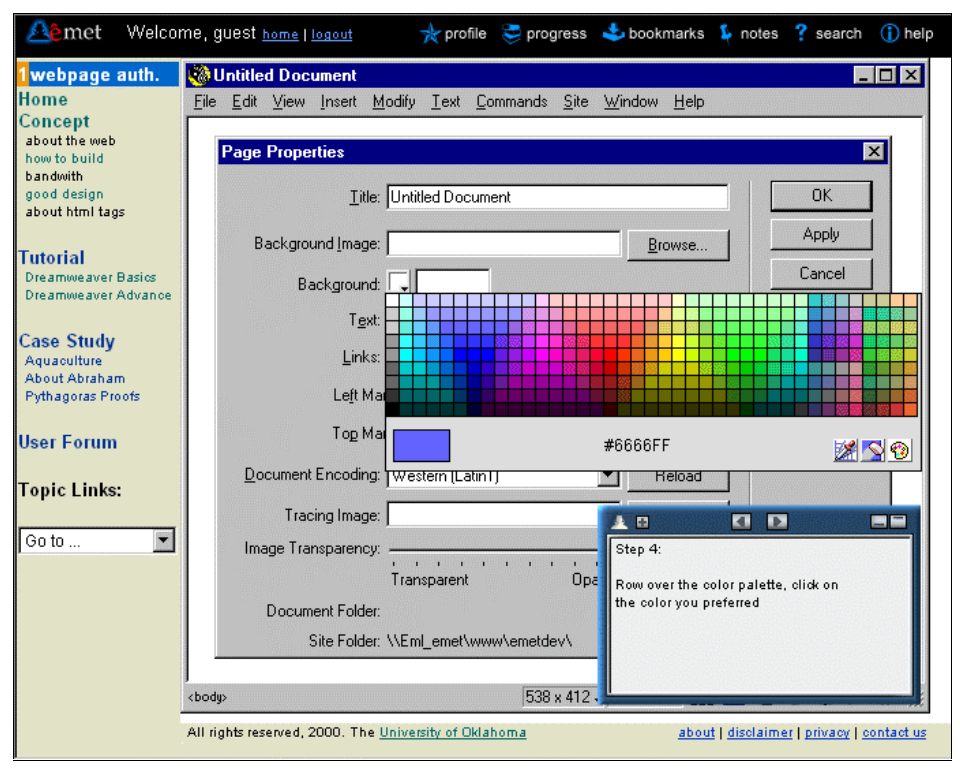

Fig. 4. Sample of an Interactive Tutorial Simulation

In addition to the three main sections to teach the user about electronic media, there is a usertracking feature that is incorporated into each of these learning methods. For example, a visit to a concept page in a topic area, such as Web Page Authoring, is tracked to determine if a user has visited the web page. This helps in accessing how often each concept page is viewed. To further elaborate, this feature allows the determination of the overall effectiveness in relation to other learning methods. With this information, future pattern indicating the preferred learning style can be examined. This is an important feature of EMET as it allows the developers to better customize to the different needs of EMET users. This tracking mechanism is similar to methods used by commercial web sites. For example, e-commerce sites also examine the behavior pattern of users at their website. Using this information, these sites can evaluate, re-distribute and improve development efforts more effectively. 


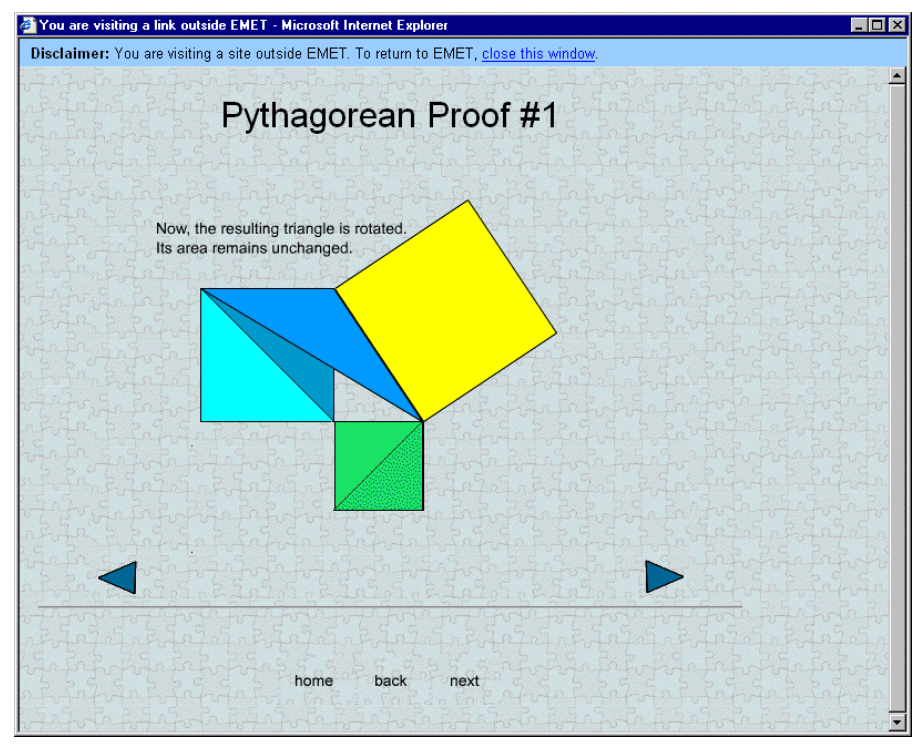

Fig. 5. Sample of a Concept Page

\section{Use of Technology}

The learning methods in EMET represent one dimension of the distance-learning site. Another dimension of EMET is shown in the use of a variety of web technologies. Among these are the Relational Database Systems (RDBMS), Open Database Connectivity (ODBC), Internet Information System (IIS), ActiveX Data Objects (ADO), Active Server Pages (ASP) and Structured Query Language (SQL). Others include a client-side scripting language such as JavaScript as well as interactive streaming media such as Macromedia Shockwave.

Although there are many similar types of technologies that can be used to develop EMET, these were used because of the following reasons. First, the combination of these technologies enables the client/server model to work across the Internet. In this model, the database assumes the role as a central repository for storing information. The client (web browser) requests data from the database on the server. Second, most of the mentioned technologies originate from Microsoft. In other words, the chosen technologies were assumed to be proven and will integrate without much difficulty. They were also assumed to be stable and well documented.

Shockwave was used because it allows the streaming of interactive media and data from the server. This is a useful feature as a work-around solution to slow Internet connections. Users do not need to wait for the entire file to be downloaded in order to view the file. Shockwave was chosen based primarily on this feature as most tutorial files have a large file size. This size is due to the amount of interactivity incorporated in the file.

The preliminary back-end database was created using the commercially available Access database from Microsoft. The database stores data associated with the activities of a registered 
user such as their academic progress, user registration information, track user clicks and the total time they spent on the web site. Tracking user clicks is important to record historical data for later profiling of students using web-based training. In order for the front-end web page to interface with this database on the server (back-end), several other technologies had to be incorporated.

In this situation, Active Server Pages (ASP) - a Microsoft technology, is used in conjunction with the ActiveX Data Objects (ADO) and SQL to create a connection to the database within the scope of the Microsoft web server (IIS). This interaction is shown in Fig. 6.

As mentioned above, the client machine requests for information from the server. In this scenario, ASP was used to dynamically generate web pages. On certain pages, ASP will interact with the database through the use of ADO. Most ADO requests to the EMET database involve queries for user-related data stored on the database such as user academic progress, user registration data and user tracking information.

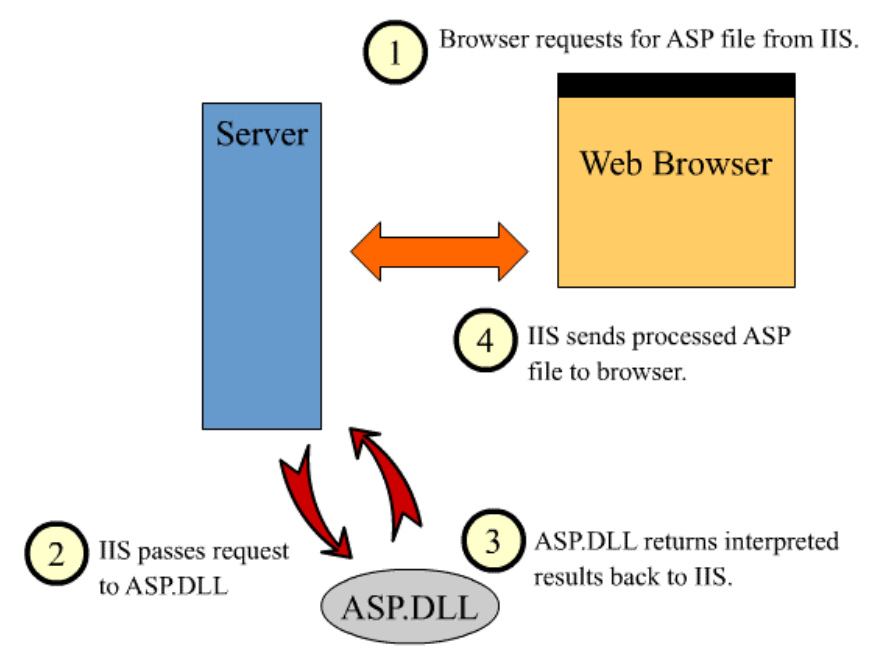

Fig. 6. ASP Page - Web Server Interaction Flowchart

\section{Software Tools Used}

Several software tools were used in the development of EMET as noted in Table 1. These tools were used to create the web pages, simulations and ASP files necessary for the client/server interactions. Notable among the software tools used are the following: Macromedia Dreamweaver, Director, Microsoft Access and an ASCII text editor such as SitePad. 
Macromedia Dreamweaver

The majority of Concept pages and Case Study pages in EMET consist of static web pages. Most of the development of these pages was created using visual HTML editors. Since there was a need for fast, easy creation of static web pages, visual (otherwise known as WYSIWYG - What You See Is What You Get) editors became one of the most used software development tool in all phases of building EMET. For example, the development of Concept pages mainly focused on the content. Therefore, the concentration is placed on building up the content and insertion of interactive multimedia elements.

Dreamweaver was used in EMET to create these static web pages because it had the following attributes - Roundtrip HTML (imports HTML documents without reformatting the code), support for DHTML, JavaScript and CSS, support for frames, and a strong site management utility that allows fast modification of web pages through use of templates, which ensure the uniformity of the layout of the EMET site.

\section{Macromedia Director}

The tutorials in the different topic areas within EMET use a technology called Shockwave. Shockwave files are generated from Macromedia Director source files. One distinct advantage of Director Shockwave is in its security. Since Shockwave is essentially a compressed compilation of the multimedia and scripting elements of a Director source file, this ensures that the end users cannot decode the downloaded Shockwave file and figure out how to disassemble the tutorial.

Macromedia Director was chosen as the major development tool for EMET tutorials also because its scripting versatility. It give developers tremendous flexibility in designing straightforward processes as well as complicated interactions, which were used to simulate various operations in the real multimedia development tools. It also has strong capabilities of importing and integrating multimedia elements, which are required by the exact resemblance between interfaces of the EMET tutorials and the real multimedia development tools.

The attractiveness of Director is further reinforced with Macromedia's streaming technology that allows the final Shockwave simulation to be viewed while parts are still in the process of downloading. This technology allows users to participate in the interaction earlier with less waiting time. Apart from streaming technology, Shockwave files have a small file size. Tutorials on the EMET web site using Shockwave have an average size of about 95 kilobytes. On a good 33.6 kbps connection, this would take an estimated download time of 20-30 seconds.

In order to view Shockwave files on a web browser, a plug-in that is available from Macromedia's web site has to be downloaded and installed. This plug-in has a small file size but requires an active connection to the Internet for the installation to be successful. Shockwave files can be linked directly or contained as an interactive element within a web page. Currently there is no direct competition to the power and functionality of Macromedia Director. 
Microsoft Access

Microsoft Access is essentially an RDBMS desktop database system, but has several limitations such as performance deficiencies when dealing with huge volumes of data. Access does not do a good job of sharing data with team members and has few tools to help optimize and manage the database. However, this RDBMS program does a good job as an initial web server-based database with its simple-to-use interface. Furthermore, by using the included Upsizing Wizard, the Access database can be conveniently upsized to SQL server database, which will be the ultimate solution for the EMET database. Access is mainly a personal database system and has a limitation as to the volume of concurrently connected users.

\section{ASCII Text Editor}

ASCII text editors are the most basic programs used in the EMET development. Text editors are used in precision scripting of ASP pages, as well as fine-tuning of web pages through hand code. For this research project, SitePad was used extensively for hand coding ASP pages. SitePad is more powerful than Notepad. It has a better text-editing environment that enables numbering of lines, color coding text for ASP, and a powerful find and replace function for simultaneous editing of multiple open text files.

\section{Summary}

The Internet is indeed a viable medium to carry out distance-learning programs. Although there are many studies being conducted to ascertain the feasibility and the best way to execute learning at a distance courseware, concrete data and standards still do not exist to guide educators in a single direction. However, efforts from traditional academic institutions and corporate training sites are converging to a point where web-based training is becoming a science by itself.

This research project named EMET was created as a controlled environment to offer a distancelearning course in multimedia development to educators. On the user level, EMET offers a variety of learning styles ranging from the static Concept pages, interactive Tutorial simulations, and skills-related Case Studies. Each learning style offers users a self-paced, non-linear learning environment.

Currently, EMET is designed for asynchronous learning but has the capability to offer more in the synchronous styled learning. From preliminary investigative studies, it was observed that most online distance-learning sites favor asynchronous learning for simplicity of management. EMET is more than just a courseware management tool to deliver content. The research site incorporates a database for web use in the back-end. The database contains among others, registered students' information and privileges, tracking data, academic progress and case studies viewed. Currently the database is used to store user information, track user clicks and keep the academic progress of the student. Tracking user clicks is important to record historical data for later profiling of students using web-based training.

EMET was developed using various web-based technologies to increase its versatility and effectiveness. The technologies used on the EMET web site were chosen based on factors

Proceedings of the 2001 American Society for Engineering Education Annual Conference \& Exposition 
ranging from stability and reliability to the possibility of future expansion. These factors emphasize the importance of matching the needs of a project, in particular the learning environment EMET, to the appropriate technologies.

\section{Bibliography}

1. Coppula, D. "Getting Hyper Over Learning." ASEE PRISM Online, 2000 (URL http://www.asee.org/pubs/html/hyper.html)

2. Tze-Leong Yew and Kurt Gramoll, "Teaching Multimedia Development to Engineering Students through Webbased Modules," ASEE Annual Conf. Proc., St. Louis, MO, Jun 19-21, 2000.

3. Roberts, J. and E. Keough. Why the Information Highway? Lessons from Open \& Distance Learning, Toronto, Canada: Trifolium Books, Inc., 1995.

\section{RUJIN CHENG}

Rujin Cheng is now a Ph. D student in Mechanical Engineering at the University of Oklahoma. She received her Bachelor of Engineering in Beijing University of Aeronautics and Astronautics in July, 1999. She also has worked for e-commerce firm developing electronic media for business in China.

\section{TZE-LEONG YEW}

Tze-Leong Yew recently graduated with a Masters degree in Mechanical Engineering at the University of Oklahoma. He received his Bachelors of Science in Mechanical Engineering from the same alma mater and is currently a member of the American Society of Mechanical Engineers (ASME) and Society of Manufacturing Engineers (SME).

\section{KURT GRAMOLL}

Kurt Gramoll is the Hughes Centennial Professor of Engineering and Director of the Engineering Media Lab at the University of Oklahoma. He has developed and published CDs and web-based sites for engineering education, K-12 instruction, and training in industry. He has started two multimedia companies for the development and distribution of technical electronic media. Dr. Gramoll received his B.S. degree in Civil engineering and M.S. degree in Mechanical Engineering, both from the University of Utah. He received his Ph.D. in Engineering Science and Mechanics from Virginia Tech. Previously, he has taught at Univ. of Memphis and Georgia Tech. 